\title{
Notes towards a surfacing of feminist theoretical turns
}

\section{Contribution to Australian Feminist Studies}

Rebecca Coleman, Sociology Department, Goldsmiths, University of London

\begin{abstract}
This article suggests that feminist theoretical turns are illuminating to study, as they make explicit how Western feminist theory is interested not only in the content of different theoretical turns, but also, relatedly, in how these turns move feminist theory in particular directions. Exploring some of the current and historical debate about turns in feminist theory, I pay particular attention to how these debates might be understood in terms of a wide range of work on the non-linear temporalities of feminist theory. I suggest that one way to understand the non-linear temporalities evident in debates over feminist theoretical turns is through a 'turn to the surface'. To explicate this suggestion, I offer a series of five indicative issues, terms and ideas, which emerge both from recent work on the surface and feminist theory, and from my attempts to think conceptually about turns, surfaces, and the relations between them. These are: (i) reflexivity; (ii) possibility; (iii) lines; (iv) knots; and (v) diagrams. I conclude by raising a number of further points that emerge through an attempt to engage in the surfacing of feminist theory.
\end{abstract}

\section{Keywords}

Feminist theoretical turns; temporality; surfaces; reflexivity; possibility; lines; knots; diagrams 


\section{Bio}

Rebecca Coleman is Senior Lecturer in the Sociology Department, Goldsmiths, University of London. Her research and teaching focuses on sensory sociology and affect, bodies, temporality (especially futures and presents), surfaces, and inventive methodologies. She has published widely in these areas and is currently developing interdisciplinary projects that cut across them. 
A good deal of discussion is currently being had on the turns to affect and the new materialism(s) in Western feminist theory. Such discussion is not new; the cultural, linguistic and postmodern turns in feminist theory in the 1980s and 1990s also generated similar debate. In questioning what and who is included and excluded in these theoretical shifts, the discussion demonstrates how attention to issues of access, omission and marginalization is vital to feminist theory, and more widely has been crucial in pointing out and intervening in normative power relations and knowledge production. It also demonstrates the significance of the development, advancement or trajectory of feminist theory to feminist theory. That is, feminist theory is interested not only in the content of different theoretical turns, but also, relatedly, in how these turns orient feminist theory in particular directions. There is debate, then, over what is at stake in a theoretical turn, how it comes to be of concern at a particular moment, and how certain matters of interest come to move feminist theory. Turns thus illuminate (struggle over) the content and movements of feminist theory; and they are also a particularly illuminating focus of study in themselves, as the debate around and about them make explicit feminist theoretical movements and trajectories.

While recognising that the content and trajectories of feminist theory cannot be fully separated, my aim in this article is to concentrate on the movements and trajectories of feminist theoretical turns. I address three main questions: How might feminist theory be understood in terms of a surface? What might a conception of the surface have to offer understandings of the trajectories and movements of feminist theory? And, more specifically, how might conceiving feminist theory in terms of a surface account for the ways in which the temporalities of feminist theory are understood in ongoing debates about theoretical turns? As these questions indicate, while I discuss some of the debates that arise about specific turns, my aim is to focus on turns more abstractly, in order to think about the temporal work that they are understood to do ${ }^{1}$. In focusing on 
temporality, I am drawing on a wide range of feminist work on narratives and stories (Hemmings 2011), generation (van der Tuin 2009, 2015, McRobbie 2008), the (nonJreproduction and 'passing on' of feminism (Roof 1997, Adkins 2004, Skeggs 2008), as well as on feminist hope (Spivak 2002, Coleman and Ferreday 2011), optimism (Berlant 2011), futurity (Grosz 1999, 2000, Coleman 2009), and transformation (Ahmed et al 2000). Much of this work challenges the notion of linear temporality as an adequate means through which to understand feminist theory, arguing that feminist theory moves not so much through 'continuous growth, smooth unfolding, or accretion' (Grosz 1999: 28), but rather through struggle, attrition, division and difference (Grosz 1999, Skeggs 2008, Spivak 2002), reflexivity (Adkins 2004), diffraction (Barad 2007, Haraway 1997, van der Tuin 2011), re-turns (Hemmings 2011, Hughes and Lury 2013), or intensive time (Coleman 2014). I draw on this work to explore the temporalities of feminist theoretical turns.

To do this, I take up what is called a 'turn to the surface' in recent cultural and social theory (Adkins and Lury 2009, Forsyth et al 2013, Coleman and Oakley-Brown, in preparation). Noting that this emerging area of interdisciplinary research is itself proposed as a 'turn', I explore how the surface is understood as 'a space [and time] of possible states' (Adkins and Lury 2009: 18); a site that is 'open, processual, non-linear and constantly on the move' (Adkins and Lury 2009: 18). I suggest that feminist turns might be understood in terms of such a surface. In order to explicate this suggestion, I offer a series of five indicative issues, terms and ideas, which emerge both from recent work on the surface and some of the feminist theory introduced above, and from my attempts to think conceptually about turns, surfaces, and the relations between them. These are: (i) reflexivity; (ii) possibility; (iii) lines; (iv) knots; and (v) diagrams. I conclude by raising a number of further points that emerge through an attempt to engage in the surfacing of feminist theory. 


\section{Debating feminist theoretical turns}

In contemporary feminist, social and cultural theory, it is perhaps the affective and new materialist turns that are most prominent, and hence currently generating most debate. Both of these turns are interdisciplinary, drawing scholars, theories, concepts, and examples from across the social sciences, humanities, arts and sciences..$^{2}$ Given these different traditions of work on and positions from which to approach affect and the new materialisms, it is unsurprising that the terms of the turns are under debate. For example, in the affective turn, some of these debates focus on the veracity, effectiveness and appropriateness of applying concepts developed in one discipline or domain to another (see Leys 2011, Papoulias and Callard 2010, Wetherell 2012, 2015). Other debates attend to how theorists are positioned in relation to the turn. Clare Hemmings (2005) has argued that while both Eve Kofosky Sedgwick $(1995,2003)$ and Brian Massumi $(1995,2002)$ - two central theorists of affect who come from different traditions and have been influential to feminist and queer theory - note that affect is inherently neither good nor bad, they nevertheless focus on 'the good affect that undoes the bad' (2005: 551). The effect, Hemmings contends, is for affect theory to 'often emerge... as a rhetorical device whose ultimate goal is to persuade "paranoid theorists" into a more productive frame of mind' (2005: 551); that is, feminist theory is encouraged to be affirmative rather than negative. This approach risks ignoring what Sianne Ngai (2005) calls 'ugly feelings', which in her analysis of film and literature she argues are more readily associated with people of colour; as Saidiya V. Hartman argues '[a]ffect, gesture, and a vulnerability to violence' has historically 'constituted blackness' (1997: 26). As such, for many who express concern over the affective turn, those who are positioned as (focusing on the) 'negative' are at once also positioned as 'belong[ing] to the past, to the already dealt with' (Hemmings 2005: 561). It is notable that those 
positioned as 'past' are very often those concerned with 'old' categories of race, gender, class - and indeed, as I discuss below, with structural problems such as patriarchy.

Similar debates are present in arguments for and assessments of the 'new materialist turn', which, while distinct, in many ways intersects with the affective turn in its interest in materiality, process and the entanglement of nature and culture. Picking up on the ways this debate engages with the movement and development of feminist theory, it is notable that the 'new' in new materialisms is often identified as of particular concern. Sara Ahmed, for example, argues that in proposing a new materialist approach as novel, advocates tend to present 'a false and reductive history of feminist engagement with biology, science and materialism' (2008: 24). Feminism has long examined, interrogated and critiqued biology and science, and thus 'we need to appreciate the feminist work that comes before us, in all its complexity' (2008: 36). As Peta Hinton and Xin Liu (2015) put it, Ahmed's argument is that the new materialism is a,

body of thought that contains a progress narrative that aims to move beyond past feminist failings, a gesture that enables its self-promotion as a novel brand and generation of (feminist) intervention wedded to a particular vision of matter's transformative potential (2015: 128) ${ }^{3}$.

I will return to the issues of progress and how feminist theory may account for both endorsements and critiques of particular turns below. Here, I want to note that struggles over turns in feminist theory are not confined to affect and the new materialisms. Discussing the linguistic turn, Kathleen Canning (1994) argues that, although often overlooked, feminist history had as important a role as the work of Foucault, Derrida and Lacan (1994: 370) in '[t]he decentering of the Western white male subject and the reformulation of subjectivity as a site of unity and conflict' (1994: 371). Similarly, from a 
feminist perspective, Frances E. Mascia-Lees, Patricia Sharpe and Colleen Ballerino Cohen (1989) caution against the postmodernist turn in anthropology, arguing that:

what appear to be new and exciting insights to those new postmodernist anthropologists - that culture is composed of seriously contested codes of meaning, that language and politics are inseparable, and that constructing the "other" entails relations of domination - are insights that have received repeated and rich exploration in feminist theory for the past forty years (1989: 11).

In ways that resonate with Ahmed's argument, then, both Canning and Mascia-Lees et al seek to re-assert the significance of previous and seemingly disregarded feminist work in establishing a theoretical turn, or in already inquiring into the issues that come to be posed as 'new and exciting' in a turn'4. Furthermore, what can also be discerned in their arguments are connections between what is posited as 'new' and 'old', what is overlooked or sidelined within a turn, and what makes a turn 'controversial' (1994: 370) and 'uneasy' (1994: 369) from a feminist perspective. ${ }^{5}$

\section{The temporalities of feminist turns}

Debates about what is 'new' and 'old' in a theoretical turn can be helpfully understood in terms of how the temporalities of feminist theory more widely are comprehended and presented within feminist work. Indeed, the 'new' and 'old' might be understood in terms of the three structures that Hemmings (2011) argues dominate what and how stories about Western feminist theory are told. These stories - which operate according to narratives of progress, loss and return - conceive the 'new' and 'old' differently, in part through how feminist theoretical work is understood in relation to the past, present and future. Briefly put, progress and loss narratives work through a similar chronological temporality but disagree on how to understand and relate to the past and 
present. In progress narratives, the past is 'temporally secured' in terms of sameness, singularity and simplicity in contrast to the present as difference, multiplicity and complexity (2011: 36). This trajectory operates through an 'emphasis on newness, transformation, and proliferation; the present is an exciting time of possibility, and we are invited to explore this "new conceptual terrain" with appropriate attitude' (2011: $56)^{6}$. Loss narratives maintain the same approach to the chronology of the past and present (2011: 61), but seek to demonstrate that feminist theory has always attended to difference, multiplicity, and has always been complex - and in fact was better (equipped, oriented, organised) in the past.

The third story Hemmings identifies offers to reconcile the feminist subjects of progress and loss narratives through a return to what is framed as an issue in the past that 'we' or 'they' can all agree is important and in need of revisiting: materialism. Interestingly for my focus here, Hemmings explains this narrative with reference to the cultural turn. Prevalent largely from the 2000s onwards (2011: 99), the return narrative indicates that materialism may either refer to a return to social reality - namely social inequality - or to science, biology and the non-human, as with the new materialisms; both areas of inquiry that proponents of the return narrative argue have been (differently) occluded by the 'textual play' of the cultural turn. In either case, Hemmings argues that the 'return narrative is predicted on, indeed enacts, a temporality in which the cultural turn is, or must be, left behind' (2011: 104); the cultural turn is over, and '[w]ounded but brave feminist materialists of both kinds can thus emerge triumphant to greet the new dawn' (2011: 109).

Hemmings highlights the importance of chronology in each of these structures of Western feminist storytelling. In some ways, these three distinct modes of storytelling assume and work via a linear temporality, in that while they all have different 
relationships to the past, present and future of feminist theory, the past, present and future nevertheless are seen to unfold into each other. Indeed, Hemmings explicates these three stories through the ways different theoretical concerns and styles are attributed to specific decades, which follow on from each other, albeit not necessarily in a smooth manner (2011: 5). However, these three stories may also be understood as demonstrating how the temporality of feminist theory is not linear, or straightforward. While a non-linear temporality might be most immediately clear in the stories of loss and return - in that as stories they highlight, differently, the salience of 'the past' of feminist theory and hence require identification with or return to a temporality that is not present - it is also evident in the progress narrative. The progress story appears to work chronologically; but it also indicates a potential disruption to a temporality that advances linearly from the past to present to future. Hemmings argues that the 'shifts in time and approach' of the progress story 'transform rather than merely adds to existing approaches, deconstructs and moves beyond as well as forward' (2011: 35). In transforming, deconstructing and moving beyond existing approaches, the progress narrative therefore does not (only) involve a smooth evolution: what the 'new', 'old', past, present and future are, and how they are understood, are not in stable relations to each other, to theoretical turns, or to feminist theorists.

Such an understanding of the non-linearity of the development of feminist theory may be identified in other engagements with and critiques of feminist progress. For example, arguments that feminism has been so successful that it is now 'repudiated' and cast as no longer needed (McRobbie 2008), point to a need to revive feminist theory and/or to maintain an attention to how it is still needed. Feminist theory is, then, at the same time, 'over', ongoing, and in need of refreshing. Analysing some of these temporalities of feminist theory, Lisa Adkins (2004) argues that feminist theory is often seen to work via a logic of reproduction across generations, and identifies concern with how this 
reproduction has failed, with younger women seen as 'refusing to inherit their feminist legacies' (2004: 430). She argues that this notion of failure relies 'on reproductive narratives whereby a linear chronological time is assumed' (2004: 428); 'because the present and the future are not being shaped by the past, feminism must (and can only) be declared as passed away' (2004: 429). Here, then, young women are positioned as 'the new' in a problematic way.

However, Adkins takes up questions posed by Judith Roof:

What if we perceived time not as linear or [...] generational but as multidirectional? What if we understand narrative as repetition, alternation, oscillation [...]? What if cause and effect can go both ways? What if action and thought are a gift that expect no return and create no debt? (Roof 1997: 87, cited in Adkins 2004: 431).

Adkins' response to these questions is to see feminism as in a reflexive relationship with both the social and epistemological. That is, feminism is in a dynamic and changing relationship with the social world, which it examines and intervenes in, and the theoretical frameworks through which its arguments are produced and contextualized (2004: 434). As such, feminism is also in a reflexive relationship with time; temporality is itself reflexive and multidirectional rather than linear. According to this approach, it is only possible to suggest that feminism has passed, and that young women - as 'the new' - have failed feminism, if feminism is understood to operate according to a linear chronology.

\section{Turns and surfaces, surfacing turns}


The purposes of the previous sections were to establish, first, that debate over feminist turns is ongoing and concerns not only the content of the turn but also the direction in which the turn is seen as taking feminist theory, and second, that in examining and telling the stories of the trajectories of feminist theory, feminist theory has pointed to the importance of understanding feminism in terms of non-linear temporality. In discussing these various positions, then, what becomes clear is that there has been and there remains struggle within feminist theory over what feminist theory 'is', 'was', might or should be. Such struggle is amplified in and through debates about theoretical turns, as turns highlight moments at which feminist theory is moving in particular directions, for good or for ill. It is on these points about the movement and diversity of feminist theory - intensified in debate about feminist turns - that I suggest that a conception of the surface might be helpfully introduced.

As indicated above, within social and cultural theory the surface is currently being proposed as a means to understand process and open-endedness, non-linearity and mobilities ${ }^{7}$. Such work challenges how the surface has conventionally been opposed to, and seen as superficial in relation to, depth (for example in some critiques of postmodernism; Jameson 1984), and has posited the surface as ontological. For example, Isla Forsyth, Hayden Lorimer, Peter Merriman and James Robinson argue that focusing on the surface 'trouble[s] the ontological principle that would have surfaces as primarily constitutive of external forms and bounded states' (2013: 1018), and ask about the 'ontological status surfaces are afforded' (2013: 1013). Adkins and Celia Lury suggest that in order to understand a changing social world, there is,

a need to redefine the relations between ontology and epistemology, and in particular a problematisation of surface-depth models that is articulated in historical understandings of representation in relation to, for example, 
hermeneutics, translation, concept formation, involvement of publics, and so on (2009: 15).

In particular, they point out how the social is (in) a state of becoming (it is 'open, processual, non-linear, and on the move') and that the arrangement and co-ordination of this new social

does not take place in relation to an externally fixed space, that is a space in which epistemology is 'above', 'behind' or 'beyond' ontology, but in relation to a surface in which the co-ordinating axes or categories of knowing are implanted, producing a space of possible states (2009: 18).

For Adkins and Lury and Forsyth et al, the surface becomes a means of understanding the social, spatial and temporal ${ }^{8}$, and how a 'space of possible states' is coordinated. It is in these two ways that I think the surface might be helpful for exploring feminist theoretical turns. I want to suggest that a turn be understood in terms of a surface; or, put slightly differently, that a turn be surfaced.

If turns are approached conceptually, they might be understood as the evolution or progression of feminist theory. Like the perhaps more familiar trope of feminist waves, turns might be thought of as indicating flow and evolution (the first wave rolling into the second wave, for example; the cultural turn flowing into the affective or new materialist turn). However, while waves certainly signal a change of focus and generate contestation and struggle, as I have discussed, for critics in particular, turns seem to suggest a rupture or break in the content and trajectory of feminist theory; a turning away from or making past of certain things (histories, issues, politics, subjects) in the turn towards other things. Indeed, in general dictionary definitions, turns are explained 
as a change of direction, the following of a different course, or the altering of focus. ${ }^{9}$ However, I want to suggest that in surfacing a turn, it is possible to understand that turn not so much as a break or rupture but rather, in Adkins and Lury's terms, as a site of 'possible states'.

There are two reasons for this surfacing of a turn. One is to attempt to take seriously both endorsements and critiques of theoretical turns - that is, to attend to debates about theoretical turns. As I have suggested, debate and struggle is crucial to the politics and ethics of feminist theory. If an aim of feminist theory is not to dampen debate but to take it (it itself and the points it raises) seriously, in what spirit might the difference indicated in debates about feminist turns be approached and conceived? Drawing through Adkins and Lury's conception of the surface as a site of 'possible states', what would be involved in seeing debates about a feminist theoretical turn as an indication of the possible states of feminist theory? How might debates about a turn occupy one surface? The second reason for suggesting a surfacing of feminist theoretical turns is to take seriously the non-linearity of feminist theory. If neither evolution nor rupture is an appropriate means of understanding the movement and development of feminist theory, how might the surface be able to account for the temporalities of feminist theory that are in Roof's terms, 'multidirectional' and involve 'repetition, alternation, oscillation'? How might the various pasts, presents and futures imagined for feminist theory that are highlighted in debates about turns be understood, mapped and coordinated?

To address these questions and explore the potential utility of the surface for conceiving feminist theory, and feminist turns more specifically, the rest of the article is organised around a series of five indicative issues, terms and ideas that have begun to emerge in the discussion so far: (i) reflexivity, or, a reformulation of the relationship between 
ontology and epistemology; (ii) possibility, or the non-linear trajectories of feminist theory; (iii) lines, or accounting for the non-linear trajectories of feminist theory; (iv) knots, or the tying together of non-linear trajectories in feminist theory, and accounting for what of a theoretical turn is seen as particularly important; and (iv) diagrams, or accounting for the coordination of a surface. While these sections inter-relate (or, better, in Karen Barad's (2007) terms, intra-act), they do not necessarily develop smoothly on from each other. Rather, following through the conception of temporality developed so far, they connect in ways that are multidirectional, and they take off from, repeat (with difference) and oscillate between each other.

\section{Reflexivity, or a reformulation of the relationship between ontology and}

\section{epistemology}

One of the characteristics of the turn to the surface that Adkins and Lury describe is a reconfiguring of the relationship between epistemology and ontology. For Adkins and Lury, in order to understand open-endedness, process, non-linearity and movement or mobility, it is necessary to both see that, and to develop an, epistemology (that) is not “'above", "behind" or "beyond" ontology' but is embedded or 'implanted' within it. To begin to unpack this idea, it is helpful to return to how debates about feminist turns highlight that feminist theory is interested not only in content, but also in how turns move feminist theory in particular directions. In other words, feminist theory is concerned not only with the world (empirical or textual, past, present or future) that is somehow 'out there', but also with itself, with the movements and trajectories of feminist theory. In Adkins' terms, feminism is therefore 'shift[ing] from a form of political consciousness constituted by subjects reflecting on socioempirical objects - a political consciousness constituted by an external reflexivity - to a self-consciousness characterized by a self or internal reflexivity' (2004: 433). 
Feminist theory might therefore be understood in terms of the surface in that there is a changing relationship between feminist theory, knowledge production, and the empirical (and/or textual) world. The shift documented by Adkins in the quotation immediately above, indicates that feminism operates not only in terms of a relationship between epistemology and ontology, where feminist theory is understood as epistemological, and the socioempirical as ontological; that is, feminist theory is not only interested in 'socioempirical objects'. Instead, feminist theory has developed a relationship with, or a 'self-consciousness' about, itself, so that feminist theory is both epistemological and ontological. Moreover, to return to Adkins' argument discussed further above, it is not only with itself that feminist theory has a reflexive relationship; it is also with the 'socioempirical'. As Adkins argues, 'rather than a spectator, feminism is implicated in and is co-determinous with the rapid transformations of cultural and social life' (2004: 441), and thus 'a distinction between self-reflexivity and the social is difficult to maintain' (2004: 434). Feminist theory is not (only) an epistemology - a way of knowing the world - but is also ontological in its imbrication in the becoming of those worlds.

\section{Possibility, or the non-linear trajectories of feminist theory}

In order to develop this idea of the reflexivity of the surface, it is helpful to remember that in the debates about the movements that feminist turns indicate or generate, the 'new' and 'old' or 'past' are seen as particularly problematic or generative. For critics of particular turns, 'the new' serves to cast other issues, positions and politics as past, over or 'already dealt with' (Hemmings 2005: 561). At the same time, and often in direct engagement with these debates about turns, a range of perspectives have sought to show how a linear model of temporality is inappropriate in understanding the trajectory of feminist theory. In my reading of these perspectives, feminist theory does not 
progress smoothly, and is capable of neither returning to or moving on from/beyond an agreed upon past. It cannot be reproduced or passed on across or between generations as if either these generations or feminism itself are stable entities. Indeed, responding to similar arguments that Adkins identifies about the 'passing away' of feminism, Beverley Skeggs (2008) refuses the 'story of "failed reproduction"' and instead posits feminist theory in terms of a 'dirty history' (2008: 684). Feminist theory is not linear but rather is a story of 'extraordinary replication' (2008: 684); 'of de- and re-inscription, of de- and re-territorialisation, of a struggle over the politics of knowledge' (2008: 684). In a different mode, but engaging with many similar issues, Iris van der Tuin has carefully analysed a generational logic within feminist theory, and developed a notion of a 'generational feminism' where change within and between feminist theories (for example between second and third waves) is understood in a non-conflictual, nondialectical, non-linear way; as generative, replicating and/or jumping $(2009,2015)$.

Feminist theory may therefore be understood in terms of 'reflexivity' not only in its selfconsciousness and relationship with the social, but also in terms of its non-linear trajectories and movements. This is important in terms of the 'reflexive', 'non-linear and non-Euclidean' logic (2009: 16) that Adkins and Lury suggest characterises the surface. Indeed, one of the ways Adkins and Lury see the reconfiguration of the relationship between epistemology and ontology is that, through the 'implantation' of 'co-ordinating axes or categories of knowing' into or onto the surface, 'a space of possible states' is produced (2009: 18). Put another way, the relationship between epistemology and ontology is collapsed or blurred so that rather than being external to that which it seeks to understand and create knowledge about, epistemology is 'implanted' into ontology. Ontology and epistemology are on and of the same surface. Adkins and Lury describe this surface as a 'topological space of all the possible states that a system can have' (2009: 16). Topology here refers both to the capacity of a surface to 'contain' or induce 
'all the possible states that a system can have', and, in Mike Michael and Marsha Rosengarten's terms, how a surface enables an 'attempt to capture heterogeneous relations and exchanges. Things that are seemingly distant [...] turn out to be far more promiscuous and can be shown to be in far closer proximity than one might initially imagine' (2012: 104).

A surface is therefore a site composed through and on which multiple and potentially diverse entities or states may (be) assemble(d). In the case of feminist theoretical turns, a surface might be a site on which (various possible versions of) the past, present and future assemble and are arranged. An understanding of feminist theoretical turns in terms of the surface may therefore be a means to take seriously proponents and opponents of a particular turn. That is, through a surfacing of feminist theoretical turns, debates and struggles about the 'possible states' of feminist theory are or can be assembled together within or on one surface. It may also be a means of thinking about the 'new', 'old', past, present and future as non-linear, multidirectional temporalities. That is, if the surface is a 'promiscuous' site where not only 'heterogeneous' but also 'seemingly distant' things might be 'in far closer proximity than one might imagine', it follows that what might be designated as far apart in linear models of time might be contiguous. Conceived as such, a feminist theoretical turn might not so much be a movement away from some issues and towards others, but a surface on which different possible temporalities exist at the same time, and are (made) proximate - or not.

\section{Lines, or accounting for the non-linear trajectories of feminist theory}

In conceiving feminist theoretical turns in terms of the surface, a number of questions are raised, including which debates and struggles are particularly intense within a turn, which versions of feminist pasts, presents and futures become dominant, and how potentially divergent positions and arguments are coordinated or arranged. In seeing a 
turn as a surface that contains and/or provokes 'all the possible states' of the system of feminist theory, a theoretical turn can be understood as a surface on which different lines of argumentation become assembled ${ }^{10}$.

To take one example of an analysis of and intervention in a feminist theoretical turn, in an article titled 'The (f)utility of a feminist turn to Foucault', Moya Lloyd (1993) points out that some feminist theorists argue that 'Foucauldian genealogy cannot illuminate systematically unequal power relations' (1993: 435). Through her careful analysis of both proponents and opponents of a feminist Foucauldian turn, Lloyd notes that 'power is a contested concept within feminism' and 'that the relation of the subject to power is problematized by any proposed recourse to Foucault' (1993: 441); an issue that is seen as 'most pressing' for 'theorising patriarchy' (1993: 442). Lloyd agrees with feminist critics that Foucault does not explicitly consider sexed and gendered power, but mobilises Foucault's conception of bio-power to offer an understanding of 'patriarchy as a particular historical configuration of power relations, without common origin' (1993: 444) and, in the process, 'to challenge, or indeed provoke, [...] a serious reflection upon, and potential rethinking of, the meaning of "patriarchy"' (1993: 445).

Lloyd's analysis and argument demonstrate how lines of argumentation concerned with what might be termed the 'old' or 'already dealt with' (Hemmings 2005: 561) exist within the feminist turn to Foucault at the same time as lines concerned with what might be termed 'the new'. That is, lines of argumentation that are focused on how patriarchy locates women in unequal power relations are, for Lloyd, at stake in any feminist Foucauldian turn at the same time as lines of argumentation that seek to 'challenge, or indeed provoke' a thinking through of what patriarchy, as a category, means. Indeed, Lloyd remarks that, 'while admittedly disruptive of certain feminist ways of theorizing', a turn to Foucault 'could also be positive to feminism', and 'intensely 
provocative and potentially productive' (1993: 457). Here, Lloyd takes up a position that might be characterized as on the side of 'the new', in that she argues for a rethinking of patriarchy ('old') through Foucault's concept of biopower ('new'). However, this rethinking might be understood not so much as a turning away from patriarchy but, as I discuss below, a turning over of it. The point here is, understood in terms of a surface, in this particular discussion of the feminist turn to Foucault, multiple lines of argumentation (past, present, 'old', 'new') exist at the same time, and things that might be cast as over according to a linear model of time (such as patriarchy), are (brought) proximate (to) things that are 'new' (biopower).

\section{Knots, or the tying together of non-linear trajectories of feminist theory, and} accounting for what of a theoretical turn is seen as particularly important While lines indicate how diverse arguments may exist at the same time on a surface, they might also be a helpful conceptual device to examine how some lines of argument become knotted, perhaps around a particular problem. After all, in debates about a turn, lines of argumentation not only exist at the same time, but get tied together in particular ways. Sophie Day, Celia Lury and Nina Wakeford describe knots as capable of 'hold[ing] together all kinds of reciprocal relationships and stories' (2014: 142) and as 'involv[ing] some kind of looping by which fastening is achieved within movement' (2014: 141).11 Knots here then, can refer to a tethering together, in a more or less secure way, of multidirectional, changing and diverse feminist trajectories in or around a particular turn. At the same time, and perhaps (although not always), how lines get tied together indicates a particularly significant issue; or what might also be referred to as a 'knotty problem'. In the above example, Lloyd's concern with patriarchy might be seen in this way.

The first sense of the knot seeks to account for how a turn signals a particular movement of feminist theory. While I have suggested that, understood in terms of a 
surface, such movements and alterations in direction are capable of existing at the same time 'within' a particular site (i.e. that which may be cast as past according to a linear model of time exists as a 'possible state' according to the non-linearity of the surface), it is nevertheless important to consider how debates about turns are debates about the orientations and directions of feminist theory; they are struggles over what lines of argumentation are carried through, and what seem of less significance. While an understanding of turns through a linear model of time might see movements within feminist theory as evolution or forgetting, in terms of the non-linear understanding of the temporalities of turns I am developing here, a turn indicates a twisting, twirling or looping of potentially diverse lines of argumentation.

In debates about the affective turn, for example, there is struggle about how lines of argumentation developed in specific disciplinary contexts are tied together; these are important in bringing to attention the specificities of particular lines of argumentation, as well as to a thinking through of whether and how it is possible to secure and stablise (even if only temporarily) potentially diverse lines of argumentation in the service of another argument - and in the service of a feminist politics. For instance, Ruth Leys argues that some cultural theories take up 'a false picture of how the mind relates to the body' (2011: 456-7) that is apparent in some scientific work on affect, contributing to what she sees as misreadings of science in cultural theory. Her position would seem to suggest that lines of argumentation developed in science need to be separated from, or at the very least taken up with great caution in, cultural theory. In her work on empathy as transnational affective relations, Carolyn Pedwell argues that 'when translated through the lens of critical theory, neuroscientific perspectives can add a productive element $[\ldots]$ to our understanding of empathetic engagement and related networks of feeling' (2014: 5). To understand the complex ways empathy operates as affective relations, a range of approaches are required. For Leys and Pedwell, then, how lines of 
argumentation developed in science and cultural theory should be taken up and tied together differ; debate over the content and direction of theoretical turns highlights whether and how lines of argumentation become knotted. In suggesting the surfacing of feminist turns then, I am not proposing to flatten out debate; surfaces are textured and patterned (Hughes and Lury 2013), they percolate and involve rifts (Michael and Rosengarten 2012) - they are knotty.

Knots are also helpful in terms of thinking about what is struggled over in debates about theoretical turns. I have already indicated how the 'new' and 'old' emerge as particularly evident in these debates, and how feminist theory moves and develops in non-linear ways. In her analysis of the stories that are told of feminist theory, for example, Hemmings notes the significance of a 'return' narrative, which 'affirm[s] a common present by affirm [ing] a shared past' (2011: 98). However, it is also possible to think of a theoretical turn as a return in another way. In their article that proposes a feminist ecological epistemology, Christina Hughes and Celia Lury (2013) argue for a return to the concept of situated knowledge, developed by Donna Haraway (1988) among others in the 1980s, as a means of 'articulating the dynamic intra-actions between human and non-human forces' (2013: 786). They explain a return to situated knowledge not so much as a going back to the 1980 s, nor an attempt to synthesise different lines of argumentation:

Rather than the currently ubiquitous narratives of 'turns' with their endless twists, ruptures and sudden encounters, such returns are products of repetition, of coming back to persistent troublings; they are turnings over. In such returnings, there is no singular or unified progressive history or approach to discover. Rather, there is the intensity of multi-dimensional trajectories, as concepts are de- and re-contextualised (2013: 787). 
As with the feminist theories discussed above, Hughes and Lury trouble an understanding of feminist theory as linear, and instead point to how it is characterized by and constituted through 'multi-dimensional trajectories' and 'repetition'. Returns are a 'coming back to persistent troublings', a 'de- and re-contextualis[ation]' of concepts so that important and difficult problems can be 'turned over'. What the concern with the 'new' and 'old' of feminist theory indicates, then, is a concern over what is seen as a 'persistent troubling', and what is being 'turned over'. The notion of return that Hughes and Lury propose, then, draws through the notion of knots that I have suggested: a twisting or twirling; a returning to and of a problem. ${ }^{12}$

It also suggests the tying together of different lines of argumentation around a particularly knotty problem. In the example above of Lloyd's article, both feminist theory as it has been concerned with social reality and feminist Foucauldian theory twist around the 'persistent problem' of power and gender inequality. This problem acts as a nub around which 'old' and 'new' concepts - patriarchy and bio-power - are brought to bear. While this example focuses on an argument advocating for a turn, an analysis of critical accounts of a feminist turn may also demonstrate this point. For example, in Ahmed's critique of the new materialism, it may be that materialism is a persistent problem that is returned to and turned over through different lines of argumentation; in Ahmed's case by a return to 'older' feminist theories of biology, science and matter, and in new materialist feminist theories by 'newer' theories of this issue. Understood in terms of a surfacing of a turn, the 'old' and 'new', supportive and critical, are brought into proximity in a knot around an - unfortunately - enduring problem.

\section{Diagrams, or accounting for the coordination of a surface}


In their explanation of the surface, Adkins and Lury note the significance of a concern with its arrangement or organisation, suggesting that the 'possible states' of a surface are not only produced but also coordinated in and through its processual nature and its reformulation of the relationship between epistemology and ontology (2009: 18). The notions of lines and knots highlight the non-linearity of the surface in how different lines of argumentation become tied in knots around particular knotty problems. In this way, knots indicate nubs, hubs or hot spots on a surface, and so draw attention to the texture and patterning of a surface - or to what might also be understood as how a surface is arranged and coordinated. Accounting for the arrangement and coordination of a surface is crucial in order to map which problems become knots/knotty, which concepts become drawn into proximity around them, which lines of argumentation are drawn through, and which fade or are dropped. That is, an account of the arrangement and coordination of a surface is to take seriously debates about a turn and to map the power relations of that surface/surfacing.

For example, to revisit Lloyd's 1993 article about the productiveness of a Foucauldian turn for feminist theory, in 2015 it may indeed seem that the concept of bio-power became particularly helpful in understanding gendered inequality and power relations, and, with the cultural turn and the new materialist turn, that the concept of patriarchy, with its roots in a materialism based in and on social reality, became less helpful. Mapping the surface of a turn can therefore tell a chronological history of the development of feminist theory - which theories and concepts become important when, and with what effects on other theories and concepts? In this sense, mapping is a project of tracking or tracing lines, and their coagulation into knots. However, mapping may have a more dynamic sense. Nanna Verhoeff, for example, has designated a performative cartography - creative, evolving and emergent through movement (2012: 145), where 'time and space unfold in practices and consequently do not work along predetermined 
lines' (2012: 146). Verhoeff's understanding of mapping is also echoed in Joe Gerlach's (2014) concept of 'vernacular mapping', which seeks to account for 'the nearly-there materialities of cartography; the non-representational coordinates of maps; affect and the virtual' (2014: 23).

The concept of the diagram is one means through which this mapping might be achieved. Indeed, in explaining Deleuze's conception of the diagram and its relation with mapping, Jakub Zdebik argues that while 'tracing' or 'tracking' movement is one of the necessary functions of the diagram, it is not its only one:

Tracing, although necessary, cannot offer anything new to thought because its function is to copy and represent what is already there. The map on the other hand - and here the map is taken away from the classical model, but without losing the classical spirit that induced it - is an exploration device, something that does not imitate but that constantly explores the unknown (Zdebik 2014: 34).

Mapping - or diagramming - is in this sense active; transformational, emergent, creative. As an 'exploration device', diagrams are a means of mapping not only what is, but also what might be: the 'possible states' that might exist on/as a surface. In terms of the surfacing of feminist theoretical turns, this might be to make connections between different lines of argumentation, and to bring into proximity concepts that might otherwise be placed at mutually exclusive positions on a linear timeline. According to the suggestion about surfacing feminist theoretical turns that I have made, mapping the surface of a turn may also enable an understanding and analysis of the non-linear temporalities of feminist theory. For example, a returning of debates about the Foucauldian turn in feminist theory might diagram the 'old' issue of patriarchy as 
important, and hence, as I've suggested, might bring patriarchy into proximity with the 'new' concept of bio-power. The surface of the Foucauldian turn is mapped not only linearly and/or chronologically, but is also coordinated non-linearly through lines and knots.

Further, Adkins and Lury point to the diagram as a non-representational sign where calculation and indexation are 'no longer determined by an external "set" [...] but by a process of deformation and modification of diagrams themselves' (2009: 17). Of significance here is the capacity of diagrams to be self-determining, so that epistemology is not external to the diagram but that the diagram is able to modify itself. Co-ordination of a surface is not external but reflexive and within or immanent to the surface. Taking up this immanence and reflexivity of a diagram, those within a debate about a feminist turn are at once inducing the turn and laying out their coordinates of and for it. The flexibility of the diagram as a mapping device suggests that the contours, lines, knots and 'possible states' of a surface will differ, or be specific to the particular position(s), tradition(s) and trajectory/ies a feminist theory is 'in'. Importantly, this is not to see a feminist theorist as in an external (or unreflexive) position to the theoretical turn - nor indeed, to necessarily prioritise the human subject ${ }^{13}$. As Hughes and Lury note, in their return to situated knowledge, 'situatedness' is understood 'not as a position or an identity, but as emergent in the diverse processes of differentiation, the patterns of movement, that constitute the moving surface or ground of figures of knowledge' (2013: 792). Feminist theorists - and the human and non-human materials that help to create her theories - are embedded within the 'moving surface' of a turn. As an 'exploration device', the diagram is thus capable of mapping out the coordination of the surface of a theoretical turn in various, situated ways, highlighting non-linear temporalities and connectivities, and performing and transforming feminist theory in the process. 


\section{Surfacing feminist theoretical turns: Concluding comments}

As this paper takes up and is involved in what is called a 'turn to the surface', I want to recognize that this turn, and the indicative suggestions made here, may themselves generate their own debate. That is, it is important to note that I am in some senses proposing a (further) turn in, to and for feminist theory - one that attempts to attend to the salience of and debates around turns themselves. However, I also want to point out that a turn to the surface is not an attempt to settle ongoing debates about epistemology and ontology, (non-)linear temporalities and spatialities, or persistent troublings. Rather, in Hughes and Lury's terms, the turn to the surface may be turnings-over of these issues; returns to debates about them.

More particularly, in suggesting that feminist theoretical turns be understood in terms of (a turn to) the surface, it is important to note that I am not arguing that the surface is a means to resolve the debates and struggles about feminist theoretical turns; such a task would be misguided in ignoring how there are feminisms rather than feminism, and how, as I've discussed, debate and struggle are integral to feminism, and indeed any political and ethical movement. Nor am I proposing the surface as a means of necessarily ensuring greater inclusion with/in feminist theory. One aspect of my argument is that a surface is capable of incorporating multiple and potentially diverse theories - it is a site of 'possible states' - and in this way it is a means of accounting for positions that critics of particular turns argue are excluded. However, at the same time, I am mindful of the potential for inclusion to collapse into what, in their analysis of key feminist articles and special issues on intersectionality, Maria Carbin and Sara Edenheim point out is an erasure of power relations. Carbin and Edenheim propose that their analysis shows that the 'intersectional turn' in feminist theory is characterized by a lack of debate. They argue that 'there is no such contestation [about intersectionality] going on, it is only stated that there are conflicts, but without any references to such debates' (2013: 239- 
240). For these authors, this lack of debate, as well as a more general 'theoretical vagueness', has led intersectionality theory to be a 'consensus-creating signifier that not only made the concept [of intersectionality] successful but also enabled an institutionalization of a liberal "all-inclusive" feminism based on a denial of power as constitutive for all subjects (and non-subjects alike)' (2013: 234) ${ }^{14}$. In introducing a 'turn to the surface', I am suggesting it neither as a turn that necessarily solves the problem of exclusion, nor presenting it as, in Carbin and Edenheim's terms, 'the feminist theory' (2013: 245) where "'everyone" feels that it fits "their way of doing research"' (2013: 245).

In suggesting the surface as a means to understand the temporalities of feminist theory, what I am indicating is that as a 'space [and time] of possible states', nothing is necessarily precluded on, in, or for a surface. However, it is also to map diagrammatically - the lines and knots of these possible states in order to attend to the power relations of a surface. This is to take seriously lines of argumentation that both propose and oppose a particular turn. In terms of the issue of the 'new' and 'old', this is to attend to what is (most strongly put) both attractive and repellant about a turn. It is to take up feminist arguments about the non-linear temporalities of feminist theories and to consider how theoretical turns seem to highlight such non-linearity especially. To paraphrase - or return - some of the questions posed by Roof (cited in Adkins (2004: 431), it is to engage with the 'multidirectional' temporalities of feminist theory, and to see debates about feminist turns as involving not so much progress or loss, but 'repetition, alternation, oscillation'.

\section{Acknowledgements}


Thanks to Lisa Adkins and Maryanne Dever for their encouragement in writing this piece. Thanks also to Anna Hickey-Moody for her comments on an earlier version, and to Bev Skeggs for suggestions of suitable literature.

\section{Bibliography}

Adkins, Lisa (2004) 'Passing on feminism: From consciousness to reflexivity?', European Journal of Women's Studies, 11 (4): 427-444.

Adkins, Lisa and Lury, Celia (2009) 'What is the empirical?', European Journal of Social Theory, 12(5): 5-20.

Ahmed, Sara (2008), 'Some Preliminary Remarks on the Founding Gestures of the "New Materialism"', European Journal of Women's Studies, 15(1), pp. 23-39.

Ahmed, Sara, Kilby, Jane, Lury, Celia, McNeil, Maureen and Skeggs, Bev (2000), 'Introduction: Thinking through feminism' in Ahmed, Sara, Kilby, Jane, Lury, Celia, McNeil, Maureen and Skeggs, Bev (eds), Transformations: Thinking Through Feminism, London and New York: Routledge.

Amato, Joseph A. (2013) Surfaces: A History, Berkley and Los Angeles: University of California Press.

Barad, Karen (2007), Meeting the Universe Halfway: Quantum Physics and the Entanglement of Matter and Meaning, Durham and London: Duke University Press. Berlant, Lauren (2011) Cruel Optimism, Durham, NC and London: Duke University Press. Canning, Kathleen (1994) 'Feminist History after the Linguistic Turn: Historicizing Discourse and Experience', Signs, 19 (2): 368-404.

Carbin, Maria and Edenheim, Sara (2013) 'The intersectional turn in feminist theory: A dream of a common language?', European Journal of Women's Studies, 20 (3): 233-248. Coleman, Rebecca (2009) The Becoming of Bodies: Girls, Images, Experience, Manchester: Manchester University Press. 
Coleman, Rebecca (2014) 'Intensive feminist theory: Representation, Materiality and Intensive Time', Women: A Cultural Review, 25(1): pp. 27-45.

Coleman, Rebecca (in preparation) 'Co-ordinating the Surface, Enacting the Social: Lines, Diagrams and Potentiality in Amazon's Speculative Shipping', Theory, Culture and Society. Submitted July 2015.

Coleman, Rebecca and Ferreday, Debra (eds.) (2011) Hope and Feminist Theory, London and New York: Routledge.

Coleman, Rebecca and Oakley-Brown, Liz (eds.) (in preparation) 'Theorising Surfaces', Theory, Culture and Society.

Day, Sophie, Lury, and Wakeford, Nina (2014) 'Number ecologies: Numbers and numbering practices', Distinktion: Scandinavian Journal of Social Theory, 15 (2): 123154.

Forsyth, Isla, Lorimer, Hayden, Merriman, Peter, Robinson, James (2013) ‘What are surfaces?', Environment and Planning A, 45: 1013-1020.

Gerlach, Joe (2014) 'Lines, contours and legends: Coordinates for vernacular mapping', Progress in Human Geography, 38(1): 22-39.

Grosz, Elizabeth (1999) 'Thinking the New: Of Futures Yet Unthought' in Grosz, Elizabeth (ed.) Becomings: Explorations in Time, Memory, and Futures Ithaca and London: Cornell University Press, pp. 15-28.

Grosz, Elizabeth (2000) ‘Deleuze’s Bergson: Duration, the Virtual and a Politics of the Future' Buchanan, Ian and Colebrook, Claire (eds) Deleuze and Feminist Theory Edinburgh: Edinburgh University Press, pp. 214-234.

Haraway, Donna (1988) 'Situated Knowledges: The Science Question in Feminism and the Privilege of Partial Perspective', Feminist Studies 14 (3): 575-599. Haraway, Donna (1997) Modest Witness@Second Millenium: FemaleMan Meets OncoMouse: Feminism and Technoscience, London: Routledge. 
Hartman, Saidiya V. (1997) Scenes of Subjection: Terror, Slavery, and Self-making in Nineteenth-century America, Oxford and New York: Oxford University Press.

Hemmings, Clare (2005) 'Invoking affect', Cultural Studies, 19 (5): 548-567.

Hemmings, Clare (2011) Why Stories Matter: The Political Grammar of Feminist Theory,

Durham and London: Duke University Press.

Hinton, Peta and Liu, Xin (2015) 'The Im/Possibility of Abandonment in New Materialist Ontologies', Australian Feminist Studies, 30 (84): 128-145.

Hughes, Christina and Lury, Celia (2013) 'Re-turning feminist methodologies: from a social to an ecological epistemology', Gender and Education, 25 (6): 786-799.

Ingold, Tim (2007) Lines: A Brief History London: Routledge.

Ingold, Tim (2010) 'Footprints through the weather-world: walking, breathing, knowing', Journal of the Royal Anthropological Institute, 16, Issue Supplement s1: S121$S 139$.

Jameson, Frederick (1984) 'Postmodernism, or the cultural logic of late capitalism', New Left Review, 146 (July-August): pp. 59-92.

King, Katie (2012) Khipu: design affections. For "Knotting in Common," Goldsmiths, University of London, Friday 15 June 2012; at: http://affectdesign.blogspot.com/, accessed $12^{\text {th }}$ August 2015.

Leys, Ruth (2011) 'The Turn to Affect: A Critique', Critical Inquiry 37 (Spring 2011): pp. 434-72.

Lloyd, Moya (1993) 'The (f)utility of a feminist turn to Foucault', Economy and Society, 2 (4): 437-460.

McRobbie, Angela (2008), The Aftermath of Feminism: Gender, Culture and Social Change, London: Sage.

Mascia-Lees, Frances E., Sharpe, Patricia and Ballerino Cohen, Colleen (1989) 'The Postmodernist Turn in Anthropology: Cautions from a Feminist Perspective', Signs, 15 (1): 7-33. 
Massumi, Brian (1995) 'The autonomy of affect', Cultural Critique, 31 (autumn 1995):

pp. 83-109.

Massumi, Brian (2002) Parables for the Virtual: Movement, Affect, Sensation, Durham, NC and London: Duke University Press.

Michael, Mike and Rosengarten, Marsha (2012) 'HIV, Globalization and Topology: Of Prepositions and Propositions', Theory, Culture and Society, 29(1-2): 93-115.

Ngai, Sianne (2007) Ugly Feelings, Harvard MA: Harvard University Press.

Papoulias, Constantina and Callard, Felicity (2010) ‘Biology’s Gift: Interrogating the Turn to Affect', Body and Society, 16(1): pp. 29-56.

Pedwell, Carolyn (2014) Affective Relations: The Transnational Politics of Empathy: Basingstoke and New York: Palgrave Macmillan.

Roof, Judith (1997) 'Generational Difficulties; or, The Fear of a Barren History', in D. Looser and E.A. Kaplan (eds) Generations: Academic Feminists in Dialogue. Minneapolis and London: University of Minnesota Press, pp. 69-87.

Sedgwick, Eve Kofosky and Frank, Adam (1995) 'Shame in the cybernetic fold: reading Silvan Tomkins', in Sedgwick, Eve Kofosky and Frank, Adam (eds) Shame and Its Sisters: A Silvan Tomkins Reader, Durham and London: Duke University Press.

Sedgwick, Eve Kofosky (2003) Touching Feeling: Affect, Pedagogy, Performativity, Durham and London: Duke University Press.

Seigworth, Greg, J. and Gregg, Melissa (2010) 'An inventory of shimmers', in Gregg, M. and Seigworth, G. J. (eds) The Affect Theory Reader, Durham and London: Duke University Press.

Skeggs, Beverley (2008) 'The dirty history of feminism and sociology: Or the war of conceptual attrition', The Sociological Review, 56(4): 670-690.

Spivak, Gayatri (2002) 'The Rest of the World', in Zournazi, M. (ed.), Hope: New Philosophies for Change, Pluto Press, Sydney, pp. 172-191. 
van der Tuin, Iris (2009). 'Jumping Generations: On Second- and Third-wave Feminist Epistemology', Australian Feminist Studies, 24 (59): 17-31.

van der Tuin, Iris (2011) “'A Different Starting Point, a Different Method”: Reading Bergson and Barad Diffractively', Hypatia, 26(1), pp. 22-42

van der Tuin, Iris (2015) Generational Feminism - New Materialist Introduction to a Generative Approach, Lanham, MD: Rowman \& Littlefield Publishers / Lexington Books. van der Tuin, Iris and Dolphijn, Rick (2012) New Materialism: Interviews and Cartographies, Ann Arbor: Open Humanities Press.

Verhoeff, Nanna (2012) Mobile Screens: The Visual Regime of Navigation, Amsterdam: Amsterdam University Press, Open Access.

Wetherell, Margaret (2012) Affect and Emotion: A New Social Science Understanding, London: Sage.

Wetherell, Margaret (2015) 'Trends in the turn to affect: A social psychological critique', Body and Society, 21 (2): 139-166.

Witz, Anne (2000) 'Whose body matters? Feminist sociology and the corporeal turn in sociology and feminism', Body and Society, 6 (2): 1-124.

Zdebik, J. (2014) Deleuze and the Diagram: Aesthetic Threads in Visual Organization, London: Bloomsbury Press.

\section{Notes}

${ }^{1}$ This article extends a short paper presented at 'Orienting feminism(s): Feminist "turns" and the political economy of knowledge production', the Centre for the Study of Women and Gender, University of Warwick, 28 th February 2014. I wish to acknowledge and thank the organisers, Maria do Mar Pereira and Kathryn Medien, as well as those who attended and submitted questions, for providing the inspiration for this longer article (which may well propose an understanding of turns different to their own). 
${ }^{2}$ For overviews of the affective turn, see for example Seigworth and Gregg 2010, and of the new materialist turn, van der Tuin and Dolphijn 2012.

${ }^{3}$ For a more detailed discussion of the new materialism as a turn in feminist theory, see Coleman (2014).

${ }^{4}$ See Witz (2000) for a slightly different account of how the body is conceptualized in feminist sociology and sociology in the 'corporeal turn'.

${ }^{5}$ Notable here is that while Canning and Mascia-Lees et al are keen to assert the importance of feminist theorizing to a turn that is happening in their broader disciplines (i.e. they are not necessarily concerned with feminism per se), Ahmed's argument is addressed to feminist theorists, who she sees as overlooking previous feminist work. It is also notable that while Canning and Mascia-Lees et al's arguments reassert the significance of feminist theory to turns in their own disciplines, many of the critiques of the affective and new materialist turns imply an unease with interdisciplinarity, as noted above.

${ }^{6}$ Here, then, is a link to Hemmings' critique of the affective turn for its encouragement of an 'affirmative' frame of mind; see above.

${ }^{7}$ On surfaces, see also Ingold $(2007,2010)$, Amato (2013) and Coleman and OakleyBrown (in preparation).

${ }^{8}$ While Adkins and Lury describe the surface as spatial here, it is also a temporal site, as I go on to discuss.

${ }_{9}^{9}$ Definitions taken from the Microsoft Word dictionary, $12^{\text {th }}$ August 2015. It is also worth noting that a further definition is 'on the turn'; 'on the point of going sour' - a definition which may be appropriate to the points made in some of the debates about theoretical turns!

${ }^{10}$ For other accounts of the relationship between lines and the surface, see Ingold (2007) and Coleman (in preparation).

${ }^{11}$ Here, they are drawing on Katie King's (2012) analysis of khipu knots. 
12 Indeed, it is important to note that Hughes and Lury propose the knot as one term that is 'designed to illustrate potential practices for developing situated knowledges' (2013: 786).

${ }^{13}$ See for example Barad (2007) on the significance of 'cuts' within positionality and boundary-making practices; for further discussions of this, see for example, Hughes and Lury (2013), Coleman (2014).

${ }^{14}$ Carbin and Edenheim's investigation demonstrates that such a situation is not so much the result of individual, or collectives of, feminist theorists but rather a consequence of the turn itself. That is, it is the intersectional turn in feminist theory that 'has created a consensus that conceals fruitful and necessary conflicts within feminism' (2013: 233). 